\title{
Proceeding
}

Supplementary Issue: Winter Conferences of Sports Science. Costa Blanca Sports Science Events, 22-23 March 2021. Alicante, Spain.

\section{Development of speed in the upper and lower extremities through games in children of 6-10 years old}

\author{
SEAD BUSHATI , MARSIDA BUSHATI \\ Department of Sport, University of Sports Tirana, Albania
}

\begin{abstract}
Introduction. Motion games are part of children's athletics and represent one of the most effective tools for acquiring specific physical education content within basic motor activities; movement games prove to be useful both during physical education classes and for children's leisure time (leisure motor activities, sports camps, etc.). The purpose of the study is; to measure, record, study and compare the state of speed quality since the age of starting school education. Also, this study will serve to better understand the state and scoring of sports talents. Methods. We have tested 100 children of which 50 were girls and 50 were boys. The intervention was done for 10 weeks. We have used 4- games. Tested: The Plate - Tapping test:25meter sprints. Discussion. The results show "25-meter sprints" that the experimental group made an improvement for the boys first classes $\leq 0.07$, second classes $\leq 0.19$, third classes $\leq 0.13$. Improvement for girls' first classes $\leq 0.13$, second classes $\leq 0.15$, third classes $\leq 0.09$. The results show the plate-tapping that the experimental group has made an improvement for boys first grade $\leq 0.30$, second grade $\leq 0.20$, third grade $\leq 0.30$. Improvement for girl's first classes $\leq 0.30$, second classes $\leq 0.30$, third classes $\leq 0.30$. Conclusions. The use of movement games during the lesson increases the degree of effective participation, develops attention and the level of interaction between students, which represents another component of the general competencies of the primary school level.
\end{abstract}

Keywords: Speed; Development; Games; Skills.

\section{Cite this article as:}

Bushati, S., \& Bushati, M. (2021). Development of speed in the upper and lower extremities through games in children of 6-10 years old. Journal of Human Sport and Exercise, 16(3proc), S905-S912. https://doi.org/10.14198/jhse.2021.16.Proc3.07

Corresponding author. Department of Sport, University of Sports Tirana, Albania. https://orcid.org/0000-0002-5529-4742

E-mail: sbushati@ust.edu.al

Abstract submitted to: Winter Conferences of Sports Science. Costa Blanca Sports Science Events, 22-23 March 2021. Alicante, Spain.

JOURNAL OF HUMAN SPORT \& EXERCISE ISSN 1988-5202.

(C) Faculty of Education. University of Alicante.

doi:10.14198/jhse.2021.16.Proc3.07 


\section{INTRODUCTION}

Albanian sport needs to know the situation in terms of speed quality, which is a basic component of many sports, which has been done by many European countries, and not only. The term speed means the ability to perform motor actions under certain conditions and in a minimum time interval. Therefore, the purpose of educating and managing the ability of speed at a young age is to create fast motor motor skills starting from the simplest to the most difficult. (Verkhoshanski 1996). To make the development of speed in children more beautiful and attractive we need to use different movement games. Through the proposed movement games, children develop their cooperative skills, they take on certain responsibilities, and they learn about tolerance, about acceptance, but also about decision-making and assume their consequences. Motion games are part of children's athletics and represent one of the most effective tools for acquiring specific physical education content Within basic motor activities; movement games prove to be useful both during physical education classes and for children's leisure time (leisure motor activities, sports camps, etc.). These aspects of adapting the curriculum to the ever-changing social reality are addressed in the concerns of specialists around the world (Carse, 2015; O'Sullivan, 2013; Jess ET all. 2016).

The purpose of the study is; to measure, record, study and compare the state of speed quality since the age of starting school education. Also, this study will serve to better understand the state and scoring of sports talents.

\section{METHODOLOGY}

Recognition of the condition will begin with children aged 6-10 years, cognition which will aim to identify and study the level of density of movement of the lower and upper extremities. So, in this study we have considered only the quality of speed and we will experiment this in both limbs. The experiment took place during the school year 2019-2020 in the primary school "Gustav Mayer", with students of first, second and third grades. To perform the experiment, the experimental group and the rest control group were assigned to each class, in total there were 200 students in the three classes who participated in the experiment, of whom 100 took part in the experiment, of these 50 were girls and 50 were boys. The proposed experiment aims to show whether the use of motion games is useful in trying to improve the quality of speed and motion density. The study involved the use of games and relays within the experimental group in order to develop speed as a motor skill.

The selection of games and relays was made to suit the level of the students. Their placement within the physical education classes was done in accordance with the teaching units planned for the development of speed as motor skills.

The study included the use of 4 games and relays based on the IAAF KIDS 'ATHLETICS - A Practical Guide within the experimental group in order to develop speed as a motor skill.

Games and relays which were used during the experiment are presented in detail in the work process. To create variety within physical education classes, these games and relays are coded and combined. The lessons contained two games and a relay or a movement game and two relays. Depending on the feedback coming from the students, they were repeated two or three times within the same lesson. The intervention was done for 10 weeks. 
As an evaluation test, "25-meter sprints" were used, starting from a standing position. Where running time and step density would be estimated. And Plate - Tapping test.

Dhe Plate - Tapping test: Plate Stroke (PLT): is used to calculate the speed of movement of an individual. The subject tries to touch 2 discs with the preferred hand in the specified order in a fast way. Two $20 \mathrm{~cm}$ plastic discs are placed on a table. The distance between the two disks with each other is $80 \mathrm{~cm}$ (the edges are $60-\mathrm{cm}$ with each other). The $10 \times 20 \mathrm{~cm}$ rectangular plate is placed in an equally remote area for both disks. The best result is considered as the end point. Matter is the time used to touch each disk for 25 times and is recorded as one tenth of a second.

$25 \mathrm{~m}$ run: The $25 \mathrm{~m}$ run was used to calculate the speed of movement of children in the lower extremity. The subject tries to run at maximum speed for $25 \mathrm{~m}$. Running started from the standing position. The stopwatch started the measurement, in the movement of the back leg and the time taken to complete the test was measured in seconds and fractions of a second. Motion games are used to develop speed as a motor skill.

\section{Game 1: The race on numbers}

Educational goals: development of reaction time, speed of execution and team spirit.

Game description: Two or more teams are formed, players sit in a row or in rows, one after the other. Children should be divided into equal numbers. Players can sit on the ground, cross-legged, or can stand on their feet. After the teachers count them in depth, they are told to recall their number. The game leader determines the direction of the run and calls a number, for example,5. Players who have this number get up and run around their row, trying to reach their starting point as quickly as possible. The team whose player reached the starting point faster scores one point. This way, all players run around their line. The one who does not run in the right direction or the one who does not run throughout the line of his / her team scores a negative point. At the end of the game, all points are added and the team with the most points is the winner.

Rules: running is performed in one direction only; running across the row of children is mandatory.

Methodical instructions: The teacher insists on directing the children to run in order to avoid injuries. Initial starting positions can be changed. The game can be repeated 2 or three times.

\section{Game 2: Running up and back through a ladder.}

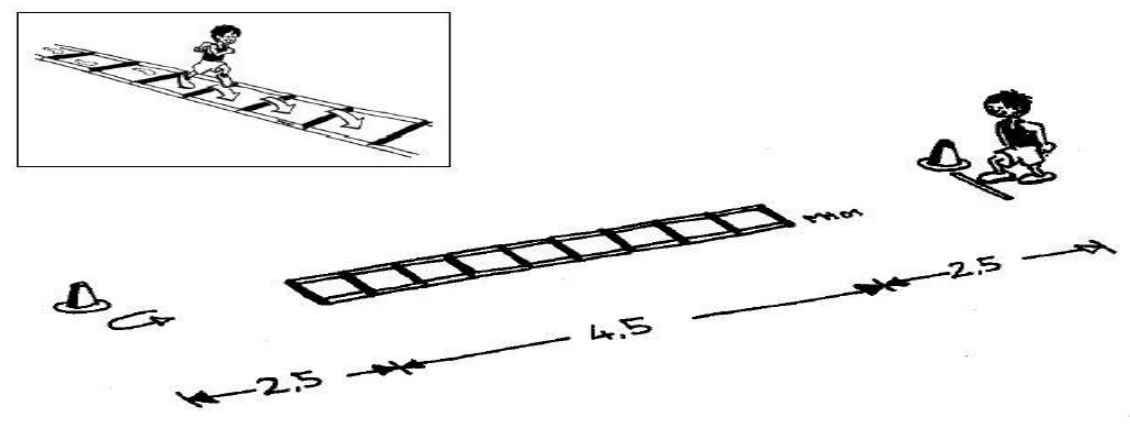

Figure 1. Runs up the stairs, site's design. 
Placed on the floor at equal distances between cones at a distance of $9.5 \mathrm{~m}$ apart (See figure above). Initially the children stand in a standing position without swaying) After the command the child runs up the stairs (distance between the wedges: $50 \mathrm{~cm}$ ) with speed to go to the second cone. After touching the cone with his hand, the child quickly turns and runs back up the stairs to the first cone. When you touch this cone, the timer stops the clock. (IAAF KIDS ATHLETICS - A Practical Guide 2010).

\section{Cross Hop}

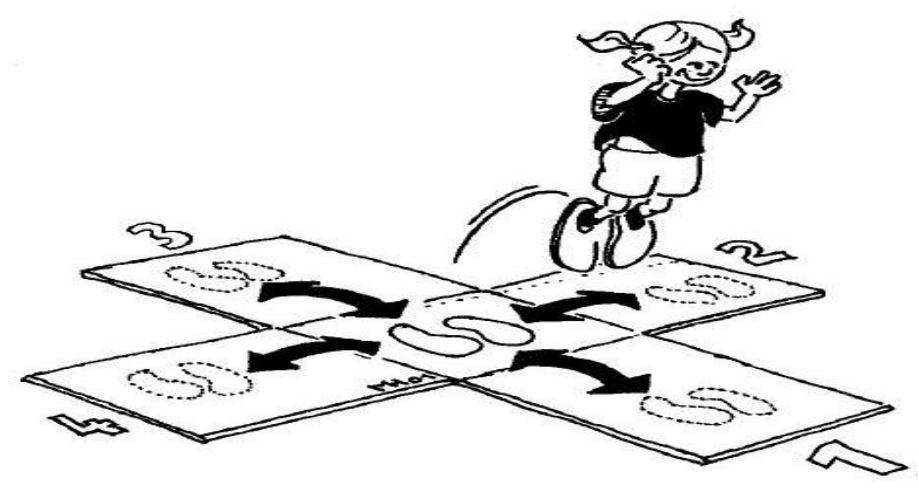

Figure 2. Two legs are thrown with a change of direction site's design.

Short description: Two legs are thrown with a change of direction Procedure From the centre of the cross throws, the participant jumps forward, backward and sideways. Specifically, the starting point is from the centre of the intersection forward, then back to the centre, then to the right and back to the centre, then left and back to the centre and finally, back and forth back to the centre (IAAF KIDS' ATHLETICS - A Practical Guide 2010).

\section{Rope Skipping}

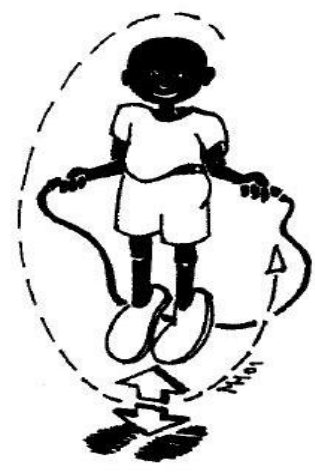

Figure 3. Rope jump site's design.

Short description: Rope jump (15 seconds) Procedure Participants stand with their feet parallel to the starting position holding the rope behind the body with both hands. In command, the rope is brought forward over the head and down in front of the body and the participant is thrown over the rope. This cyclic process is repeated as long as possible in 15 seconds. This event is intended exclusively for the First Age Group. The child should be thrown on both feet. Each child performs two "tests" (IAAF KIDS' ATHLETICS - A Practical Guide 2010). 


\section{RESULTS AND DISCUSSIONS}

In this study was performed the measurement Plate - Tapping test and running $25 \mathrm{~m}$ for ages 6-10 years.

The initial and final test results were statistically processed so that we could objectively assess whether the use of motion games and relays could contribute to improving engine quality display indices at speed.

\section{Plate - Tapping}

Table 1. The first test results for groups boys.

\begin{tabular}{|c|c|c|c|c|c|}
\hline \multicolumn{6}{|l|}{ ys } \\
\hline \multicolumn{3}{|c|}{ The control group $(n=25)$} & \multicolumn{3}{|c|}{ The experimental group $(n=25)$} \\
\hline Plate - Tap & & & Plate - Tap & & \\
\hline Classes 1 & Classes 2 & Classes 3 & Classes 1 & Classes 2 & Classes 3 \\
\hline $19.80 \mathrm{sec}$ & $19.20 \mathrm{sec}$ & $18.50 \mathrm{sec}$ & $19.80 \mathrm{sec}$ & $19.20 \mathrm{sec}$ & $18.50 \mathrm{sec}$ \\
\hline
\end{tabular}

Table 2. The first test results for groups girls.

\begin{tabular}{|c|c|c|c|c|c|}
\hline \multicolumn{6}{|l|}{ irls } \\
\hline \multicolumn{3}{|c|}{ The control group $(n=25)$} & \multicolumn{3}{|c|}{ The experimental group $(n=25)$} \\
\hline \multicolumn{3}{|c|}{ Plate - Tapping } & \multicolumn{3}{|c|}{ Plate - Tapping } \\
\hline Classes 1 & Classes 2 & Classes 3 & Classes 1 & Classes 2 & Classes 3 \\
\hline $20 \mathrm{sec}$ & $19.50 \mathrm{sec}$ & $18.93 \mathrm{sec}$ & $20 \mathrm{sec}$ & $19.50 \mathrm{sec}$ & $18.93 \mathrm{sec}$ \\
\hline
\end{tabular}

The test results were statistically processed so that we could objectively assess whether there is a difference between ages and gender in the quality of the upper and lower extremities.

From the table above we can conclude that, in the initial tests, both groups of boys and girls achieved similar performance. This fact shows us that students have a similar level of development, specific to their age group. From the table above we can conclude that, in the test done it turns out that third graders are better in the quality of speed in the upper extremities than second and first graders. Analysis of the results between boys and girls in all three classes shows that boys managed to complete the test faster than girls.

Table 3. The final test results for the groups of boys.

\begin{tabular}{|c|c|c|c|c|c|}
\hline \multicolumn{6}{|l|}{ oys } \\
\hline \multicolumn{3}{|c|}{ The control group $(n=25)$} & \multicolumn{3}{|c|}{ The experimental group $(n=25)$} \\
\hline \multicolumn{3}{|c|}{ Plate - Tapping } & \multicolumn{3}{|c|}{ Plate - Tapping } \\
\hline Classes 1 & Classes 2 & Classes 3 & Classes 1 & Classes 2 & Classes 3 \\
\hline $19.70 \mathrm{sec}$ & $19.00 \mathrm{sec}$ & $18.20 \mathrm{sec}$ & $19.40 \mathrm{sec}$ & $18.80 \mathrm{sec}$ & $17.90 \mathrm{sec}$ \\
\hline
\end{tabular}

Table 4. The final test results for the groups of girls.

\section{Girls}

The control group $(n=25)$
\begin{tabular}{|l|ll|l|l|l|}
\hline Plate - Tapping & \multicolumn{4}{l|}{ The experimental group $(n=25)$} \\
\hline Classes 1 & Classes 2 & Classes 3 & Plate - Tapping & \\
\hline $19.90 \mathrm{sec}$ & $19.40 \mathrm{sec}$ & $18.80 \mathrm{sec}$ & $19.60 \mathrm{sec}$ & $19.10 \mathrm{sec}$ & $18.50 \mathrm{sec}$ \\
\hline
\end{tabular}


The results of the experimental group are significantly better than the control group. The final test results recorded by the boys and girls group show a favourable evolution for both groups involved in the experiment. From this point of view, both the control group and the experimental group recorded a progress, but the experimental group gave a better performance. The results show that the experimental group has made an improvement for boys first grade $\leq 0.30$, second grade $\leq 0.20$, third grade $\leq 0.30$. Improvement for girl's first classes $\leq 0.30$, second classes $\leq 0.30$, third classes $\leq 0.30$. As a result of the statistical analysis performed within the groups, we can claim that the method used in the experimental group was more efficient. This shows that the use of movement games during the physical education class increases the degree of effective participation, the development of attention and the level of interaction between students, as well as the development of the quality of speed in the upper extremities.

\section{Running $25 \mathrm{~m}$}

Table 5. The first test results for groups boys.

\begin{tabular}{|c|c|c|c|c|c|}
\hline \multicolumn{6}{|l|}{ Boys } \\
\hline \multirow{2}{*}{\multicolumn{3}{|c|}{$\begin{array}{l}\text { The control group }(n=25) \\
\text { Speed } 25 \mathrm{~m}\end{array}$}} & \multicolumn{3}{|c|}{ The experimental group $(n=25)$} \\
\hline & & & Speed $25 \mathrm{~m}$ & & \\
\hline Classes 1 & Classes 2 & Classes 3 & Classes 1 & Classes 2 & Classes 3 \\
\hline $6.99 \mathrm{sec}$ & $6.86 \mathrm{sec}$ & $6.77 \mathrm{sec}$ & $6.99 \mathrm{sec}$ & $6.86 \mathrm{sec}$ & $6.77 \mathrm{sec}$ \\
\hline
\end{tabular}

Table 6. The first test results for groups girls.

\begin{tabular}{|c|c|c|c|c|c|}
\hline \multicolumn{6}{|l|}{ Girls } \\
\hline \multirow{2}{*}{\multicolumn{3}{|c|}{$\begin{array}{l}\text { The control group }(n=25) \\
\text { Speed } 25 \mathrm{~m}\end{array}$}} & \multicolumn{3}{|c|}{ The experimental group $(n=25)$} \\
\hline & & & Speed $25 \mathrm{~m}$ & & \\
\hline Classes 1 & Classes 2 & Classes 3 & Classes 1 & Classes 2 & Classes 3 \\
\hline $7.00 \mathrm{sec}$ & $6.92 \mathrm{sec}$ & $6.80 \mathrm{sec}$ & $7.00 \mathrm{sec}$ & $6.92 \mathrm{sec}$ & $6.80 \mathrm{sec}$ \\
\hline
\end{tabular}

As in the Plate - Tapping test in the initial test the boys gave a better performance than the girls in the $25 \mathrm{~m}$ speed test. The third graders performed better than the first and second graders.

The table above shows that in this initial test, both groups of boys and girls achieved similar performance. This fact shows that students have a similar level of development, specific to their age group.

Speed as a complex conditioning ability, improves from the age of 5 until full maturity with similar dynamics of speed development in both boys and girls (Dhimitraq Skënderi 2012) and at the age of 8 to 12 years the speed undergoes a marked development (Sharkey 1986)

Table 7. The final test results for the groups of Boys.

\begin{tabular}{|c|c|c|c|c|c|}
\hline \multicolumn{6}{|l|}{ oys } \\
\hline \multirow{2}{*}{\multicolumn{3}{|c|}{$\begin{array}{l}\text { The control group }(n=25) \\
\text { Speed } 25 \mathrm{~m}\end{array}$}} & \multicolumn{3}{|c|}{ The experimental group $(n=25)$} \\
\hline & & & Speed $25 \mathrm{~m}$ & & \\
\hline Classes 1 & Classes 2 & Classes 3 & Classes 1 & Classes 2 & Classes 3 \\
\hline $6.72 \mathrm{sec}$ & $6.69 \mathrm{sec}$ & $6.58 \mathrm{sec}$ & $6.65 \mathrm{sec}$ & $6.50 \mathrm{sec}$ & $6.45 \mathrm{sec}$ \\
\hline
\end{tabular}


Table 8. The final test results for the groups of Girls.

\begin{tabular}{|c|c|c|c|c|c|}
\hline \multicolumn{6}{|l|}{ Girls } \\
\hline \multirow{2}{*}{\multicolumn{3}{|c|}{$\begin{array}{l}\text { The control group }(n=25) \\
\text { Speed } 25 \mathrm{~m}\end{array}$}} & \multicolumn{3}{|c|}{ The experimental group $(n=25)$} \\
\hline & & & Speed $25 n$ & & \\
\hline Classes 1 & Classes 2 & Classes 3 & Classes 1 & Classes 2 & Classes 3 \\
\hline $6.91 \mathrm{sec}$ & $6.85 \mathrm{sec}$ & $6.70 \mathrm{sec}$ & $6.78 \mathrm{sec}$ & $6.70 \mathrm{sec}$ & $6.61 \mathrm{sec}$ \\
\hline
\end{tabular}

The results of the experimental group are significantly better than the control group. The final test results recorded by the boys and girls group show a favourable evolution for both groups involved in the experiment. From this point of view, both the control group and the experimental group made progress, but in the experimental group gave a better performance. The results show that the experimental group made an improvement for the boys first classes $\leq 0.07$, second classes $\leq 0.19$, third classes $\leq 0.13$. Improvement for girls first classes $\leq 0.13$, second classes $\leq 0.15$, third classes $\leq 0.09$. As a result of the statistical analysis performed within the groups, we can claim that the method used in the experimental group was more efficient. This shows that the use of movement games during the physical education class increases the degree of effective participation, the development of attention and the level of interaction between students, as well as the development of the quality of speed in the upper extremities.

\section{CONCLUSION}

Speed as a complex conditioning ability, improves from the age of 5 until full maturity with similar dynamics of speed development in both boys and girls (Dhimitraq Skënderi 2012) and at the age of 8 to 12 years the speed undergoes a marked development (Sharkey 1986).

In children of this age group, the ability for dense actions per unit of time stands out and is determined by genetic factors. Several studies have showed that levels of physical activity are inherited within the family (Craig et al., 2013, Freedson and Evenson, 1991, Jago et al., 2010, Moore et al., 1991).

The use of movement games throughout the school year, which are selected according to the characteristics of the age and gender of the students, will lead to the achievement of the general competencies presented in the school curriculum.

The use of movement games during the lesson increases the degree of effective participation, develops attention and the level of interaction between students, which represents another component of the general competencies of the primary school level.

The use of games and their use during the lesson aims to transform the content of the lesson. Thus, physical exercise becomes a tool for maintaining health and a tool for social integration through sport.

\section{REFERENCES}

Carse N., (2015) Primary teachers as physical education curriculum change agents, European Physical Education Review Vol. 21, no. 3, pp.309-324. https://doi.org/10.1177/1356336X14567691

Currie J ,L. (2013) Teaching Physical Education in Primary School - An integrated health perspective, Publisher: ACER Press, 112-118.

Gloria R Gogola 1, Paul F Velleman, Shuai Xu, Adrianne M Morse, Barbara Lacy, Dorit Aaron, (2013)Hand dexterity in children: administration and normative values of the functional dexterity test, 
Jurnal of Hand Surgery Journal Club, Vol.38, P2426-2431. https://doi.org/10.1016/j.jhsa.2013.08.123

Gombettav.(1996). How to develop sport-specific speed, sports choch,vol.19.pp.22-24.

Griggs, G. (2012), An Introduction to Primary Physical education, Publisher: Routdlege, 151-161. https://doi.org/10.4324/9780203131886

Iconomescu T.M, (2013) Didactics of Physical Education and Sport / Course notes, Publisher: Zigotto, Galati.

Iconomescu TM., Talaghir LG. (2014) Teaching approach to enhance motor skills for students in primary school, Procedia - Social and Behavioural Sciences, Volume 152, 746-751. https://doi.org/10.1016/j.sbspro.2014.09.314

Ioan Sabin Sopa ,Marcel Pomohaci, (2017) Study regarding the development of agility skills of students aged between 10 and 12 years old , Timisoara Physical Education and Rehabilitation Journal, Vol. 9. https://doi.org/10.1515/tperi-2016-0009

Jess M., Carse N., Keay J, (2016) The primary physical education curriculum process: more complex that you might think!!, Education 3-13 International Journal of Primary, Elementary and Early Years Education, Vol. 44, no. 5, 502-512. https://doi.org/10.1080/03004279.2016.1169482

O'Sullivan M., (2013)New directions, new questions: relationships between curriculum, pedagogy, and assessment in physical education, Sport Education and Society, Vol. 18, no.1, 1-5. https://doi.org/10.1080/13573322.2012.719868

Plisk S.S., (2000). Speed, agility and speed endurance development, In T.R. Beachle and R.W. Earle (Eds.), Essential of Strength Training and Conditioning, Champaign, IL: Human Kinetics.

Twist P.W., Benicky D. (1996). Conditioning lateral movements for multi-sport athletes: Practical strength and speed drills, Strength andConditioning 18(5), pp. 10-19. https://doi.org/10.1519/10736840(1996)018<0010:CLMFMS>2.3.C0;2

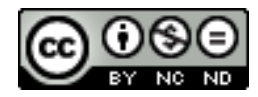

This work is licensed under a Attribution-NonCommercial-NoDerivatives 4.0 International (CC BY-NC-ND 4.0). 